\title{
Identifikasi Jenis-Jenis Tumbuhan Sekitar Mata Air Tiga Rasa Sebagai Upaya Konservasi Air Di Gunung Muria Kudus
}

\author{
Abdul Malik ${ }^{1}$, Niken Kusumarini1 ${ }^{1}$ \\ ${ }_{1}$ Program Studi Biologi, Fakultas Sains dan Teknologi, UIN Walisongo Semarang \\ Email: ${ }^{1}$ abdul_malik@walisongo.ac.id
}

\begin{abstract}
The Springs of Tiga Rasa Rejenu is one of the springs located at one of the peaks of the seven peaks in the Muria mountains. The Tiga Rasa Springs are located at the peak of Argo Wiloso Rejenu, Kudus Regency. The diversity of vegetation around the Tiga Rasa Springs has an important role in the sustainability of springs source and discharge. This study aims to determine the composition of plants, vegetation forms, the index of importance value of vegetation components, and the abiotic environment impact around the springs. The method used is explorative descriptive analysis by dividing the area into four research stations based on the direction of the eye. At each research station there are three sample plots. Each station is divided into three sampling points with a size of $20 \mathrm{~m} \times 20 \mathrm{~m}$ for trees, $10 \mathrm{~m} \times 10 \mathrm{~m}$ for poles, and $5 \mathrm{~m} \times 5 \mathrm{~m}$ for saplings and $2 \mathrm{~m} \times$ $2 \mathrm{~m}$ for seedlings. Abiotic environmental parameters measured are air temperature and humidity, light intensity, soil temperature, soil $\mathrm{pH}$, total dissolved solids, and water salinity. The research results around the Tiga Rasa Rejenu spring are that the $H^{\prime}$ values at the highest level of seedlings is fern Diplazium esculentum, the $H^{\prime}$ values at the highest level of saplings is the royal palm tree Roystonea regia, and the $H^{\prime}$ values at the highest level of poles and trees is Pterocarpus indicus. At all stations obtained average H'value is 1.96 then the vegetation around the Tiga Rasa spring classified to medium plant diversity and medium community stability. Abiotic factors effect on the environmental conditions around the Tiga Rasa Rejenu springs.
\end{abstract}

Keywords: Abiotic, Tiga Rasa spring, $H^{\prime}$ value, vegetation

\section{Pendahuluan}

Air Tiga Rasa merupakan salah satu sumber mata air alami yang berada di kawasan Gunung Muria tepatnya di Rejenu Desa Japan, Kecamatan Dawe, Kabupaten Kudus. Sumber mata air alami merupakan aliran air tanah yang muncul ke permukaan tanah secara alami akibat adanya perpotongan aliran air bawah tanah oleh topografi pada wilayah tersebut (Azizah 2017). Mata Air Tiga Rasa memiliki ketinggian 1.150 mdpl dan termasuk dalam kawasan wisata alam di Pegunungan Argo Jembangan (salah satu nama puncak dari 7 puncak yang ada di Gunung Muria). Letaknya kurang lebih $3 \mathrm{~km}$ dari Makam Sunan Muria Kudus (Raden Umar Said). Raden Umar Said merupakan putra dari Sunan Kalijaga Demak (Raden Said) yang menyebarkan Agama Islam di semenanjung pegunungan Muria Kudus.
Di sekitar Mata Air Tiga Rasa terdapat area Makam Syekh Hasan Sadzali, beliau merupakan santri setia dari Sunan Muria yang turut serta menyebarkan ajaran agama Islam kepada penduduk di kawasan lereng Muria (Sari 2010). Menurut Falah (2012), Syekh Hasan Sadzali berasal dari Negeri Irak (Baghdad). Oleh karena itu, selain banyak peziarah yang datang ke Makam Sunan Muria, tak lupa juga peziarah berziarah ke Makam Syekh Sadzali.

Secara Geografis Mata Air Tiga Rasa berada di Rejenu Kecamatan Dawe Kabupaten Kudus. Kecamatan Keling, Jepara berada di sisi sebelah utara, Kecamatan Margoyoso, dan Tayu berada di sisi Timur, Kecamatan Bae, dan Dawe Kudus berada di sisi selatan. Kemudian di sebelah Barat terdapat Kecamatan Mayong, dan Batealit, Jepara. Gunung Muria ketinggian 1602 mdpl dengan suhu 20-33 $\mathrm{C}^{0}$ dan memiliki luas 
kurang lebih dari 293.297, 189 hektar (Widjanarko 2016). Secara geologi kawasan Gunung Muria berupa sesar yang mempunyai pola umum dari timur laut-barat daya dan dari barat laut - tenggara sedangkan pada bagian utara terdapat analisis seismik refleksi di Laut Jawa yang mirip dengan seismik pada Gunung Muria (McBirney et al. 20013).

Gunung Muria terletak di tiga Kabupaten yaitu Kabupaten Kudus, Pati dan Jepara. Kawasan Muria tepatnya terletak di sisi selatan berada di wilayah kecamatan Dawe kabupaten kudus, Kecamatan Keling Kabupaten Jepara di sisi barat laut, dan Kecamatan Gembong Kabupaten Pati di sisi timur. Gunung Muria memiliki luas total kurang lebih 293.297,189 hektar dengan ketinggian $1602 \mathrm{mdpl}$ dan suhu 20-33 C. Luas hutan keseluruhan Gunung Muria mencapai 69.812,08 hektar, terdiri dari wilayah Kabupaten Jepara 20.096,51 hektar, Kabupaten Pati 47.338 hektar dan Kabupaten Kudus 2.377,57 hektar. Hutan yang terdapat di kawasan muria dibagi menjadi dua yaitu hutan produksi dan hutan lindung.

Muria sebagai salah satu hutan lindung yang harus dijaga kelestariannya oleh masyarakat Jawa Tengah. Berdasarkan data dari Muria Studies dan KPH Pati (2010), bahwa terdapat 80 jenis pohon, palem-paleman, dan rumput-rumputan. Jenis pohon hasil dari penanaman, seperti Mahoni (Swietenia mahagony) yang ditanam tahun 1942, Tusam (Pinus merkusii) yang ditanam tahun 1944, Sengon (Albizzia falcate) dan Kopi yang mulai ditanam tahun 1942. Dari sisi fauna, dijumpai paling tidak lima jenis Ular Senduk (Kobra Jawa), Sanca Hijau, Welang, Weling, Kera, Landak, Tupai, Trenggiling, Babi Hutan, Musang, Ayam Hutan, Kijang, Macan Tutul, Burung Trucuk, Kutilang, Kacer Kembang, Lutung, Cucak Hijau, Cucak Kembang, Ledekan, Elang, Rangkong, Plontang, Tekukur, Gelatik, Kuntul, Prenjak, Perkutut, Ciblek, Burung Madu, Truntung, Pelatuk Bawang, Branjangan, Burung Hantu, dan Brubut. Pada tahun 1998 masih terlihat adanya jejak keberadaan Harimau Jawa (Pantera tigris sondaica) di kawasan
Pegunungan Muria. Harimau Jawa sendiri merupakan predator paling kuat. Selain Harimau Jawa di pegunungan Muria juga menyimpan potensi keberadaan satwa langka yaitu, Elang Jawa (Spizaetus bartelsi) atau yang lebih dikenal sebagai burung Garuda.

Melimpahnya keanekaragan hayati dan pentingnya fungsi hutan lindung bagi keseimbangan ekosistem maka perlu ada upaya untuk melakukan konservasi hutan lindung di Muria. Berdasarkan Peraturan Pemerintah Republik Indonesia nomor 24 tahun 2010 tentang penggunaan kawasan hutan menjelaskan bahwa hutan lindung adalah kawasan hutan yang mempunyai fungsi pokok sebagai perlindungan sistem penyangga kehidupan untuk mengatur tata air, mencegah banjir, mengendalikan erosi, mencegah intrusi air laut, dan memelihara kesuburan tanah. Akan tetapi fenomena yang ada di lapangan telah terjadi penggundulan hutan lindung dengan indikasi adanya punurunan luas hutan lindung di Kabupaten Kudus.

Mata Air Tiga Rasa terletak pada kawasan Hutan Lindung yang dikelola oleh Perhutani (Persero). Hutan Lindung yang berada di kawasan Gunung Muria termasuk dalam pengelolaan Kesatuan Pengelolaan Hutan (KPH) Pati dan pelaksananya adalah Resort Pemangkuan Hutan (RPH) Ternadi. Luas kawasan Hutan Lindung Pegunungan Muria 2.334,8 $\mathrm{Ha}$, dan pemanfaatan kawasan wisata dengan luas 221.3 Ha (Widjanarko dan Wismar'ein 2011). Berdasarkan data dari Muria Studies (2010), keberadaan Mata Air Tiga Rasa yang berada di dalam kawasan hutan lindung menjadikan kawasan tersebut menjadi kawasan yang dijaga dan harus dikonservasi. Hutan lindung di kawasan muria mempunyai kekayaan dan keanekaragaman hayati (tumbuhan dan hewan). Konservasi merupakan suatu perlindungan terhadap alam dan makhluk hidup lainnya. Sesuatu yang mendapat perlindungan maka dengan sendiri akan terwujud kelestarian.

Pada tahun 2005, kawasan air tiga rasa mengalami pengembangan menjadi tujuan wisata alam. Pembangunan sarana wisata 
seperti kamar mandi dan WC, lahan parkir, gardu duduk dan saung untuk para pedagang memerlukan ruang yang luas, sehingga dilakukan penebangan pada beberapa tumbuhan yang terdapat di bawah kawasan air tiga rasa. Keberadaan vegetasi di kawasan sekitar air tiga rasa mempunyai peranan penting untuk menjaga kelestarian sumber mata air itu sendiri. Penebangan pohon, perusakan jenisjenis tumbuhan dan perubahan tata guna lahan berpengaruh terhadap ketersediaan air dan dapat mendegradasi sumber mata airnya. Hal ini terjadi karena pembukaan hutan atau pengrusakan vegetasi pada suatu lahan menyebabkan kemampuan tanah untuk menyimpan air hujan menjadi berkurang.

Vegetasi merupakan unsur pokok dalam usaha konservasi tanah dan air. Keberadaan hutan akan menjadikan permukaan tanah tertutup serasah dan humus. Tanah menjadi berpori, sehingga air mudah terserap ke dalam tanah dan mengisi persediaan air tanah. Oleh karena itu, perlu dilakukan analisis vegetasi mengenai keberadaan tumbuhan di kawasan sekitar Air Tiga Rasa. Analisis vegetasi dalam ekologi tumbuhan adalah cara untuk mempelajari struktur vegetasi dan komposisi jenis tumbuhan. Analisis vegetasi bertujuan untuk mengetahui komposisi jenis (susunan) tumbuhan dan bentuk (struktur) vegetasi yang ada di wilayah yang dianalisis. Analisis mengenai vegetasi di kawasan sekitar mata air sangat diperlukan sebagai salah satu langkah awal konservasi dan pemulihan lahan apabila di masa mendatang mengalami perubahan yang mengarah pada alih fungsi lahan. Tujuan dari penelitian ini adalah untuk mengetahui komposisi penyusun vegetasi, indeks nilai penting dan faktor lingkungan abiotik yang mempengaruhi vegetasi di sekitar mata Air Tiga Rasa.

\section{Metode}

Penelitian ini menggunakan metode deskriptif eksploratif. Lokasi penelitian terletak di kawasan Mata Air Tiga Rasa Rejenu, Kecamatan Dawe, Kabupaten Kudus. Identifikasi spesimen dilakukan di laboratorium Biologi UIN Walisongo Semarang. Alat dan bahan yang digunakan yaitu, termometer, soil tester, tali plastik, meteran, patok, kantong plastik besar, gunting tanaman, kertas label, alkohol 70\%, koran, sasak, kamera, dan ATK.

Penentuan stasiun penelitian dilakukan berdasarkan penarikan garis transek mengikuti 4 arah penjuru mata angin yaitu utara (stasiun I), timur (stasiun II), selatan (stasiun III) dan barat (stasiun IV) dengan pusat transek pada mata Air Tiga Rasa Rejenu (Gambar 1).

\section{Pengambilan Sampel Penelitian}

Metode yang digunakan dalam penelitian ini adalah petak bersarang, setiap stasiun penelitian dibagi menjadi 3 titik sampling dan di setiap titik sampling dibuat 3 petak plot, sehingga setiap stasiun penelitian terdapat 9 petak plot (Gambar 2).

Faktor koreksi vegetasi (FV) diperoleh dengan menggunakan perhitungan indeks keanekaragaman Shannon dengan metode jalur

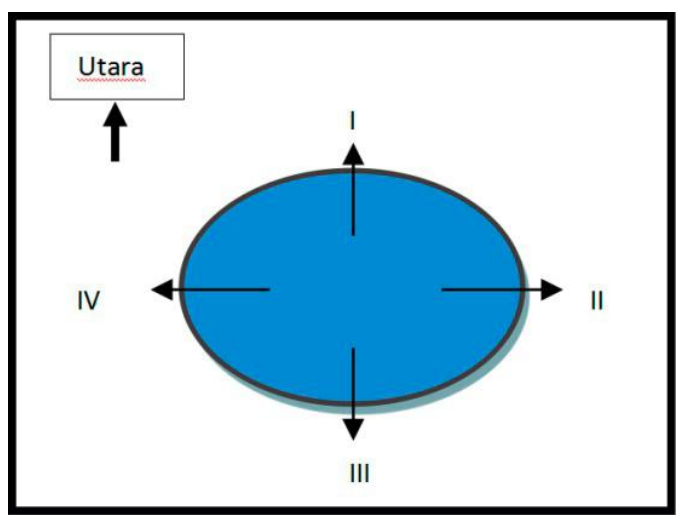

Gambar 1. Skema Penentuan Stasiun Penelitian

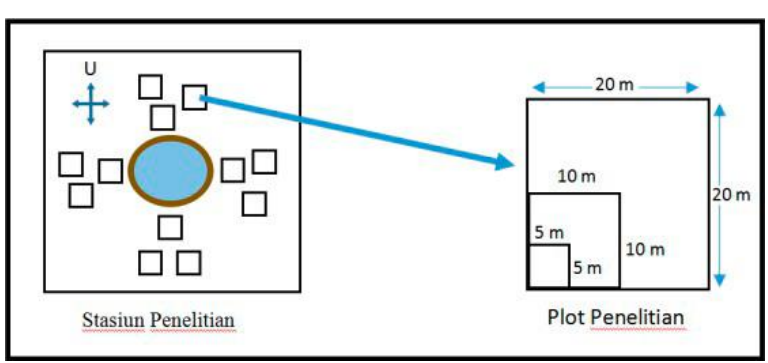

Gambar 2. Skema Pengambilan Sampel Penelitian 
berpetak. Pada metode ini dibuat jalur dengan petak-petak pengamatan yang terdiri dari petak ukuran 2 x 2 m yang digunakan untuk menganalisis vegetasi tingkat semai dan vegetasi bawah. Untuk petak 5 x $5 \mathrm{~m}$ digunakan untuk menganalisis vegetasi tingkat pancang, petak ukuran $10 \times 10 \mathrm{~m}$ untuk analisis vegetasi tingkat tiang dan petak $20 \times 20 \mathrm{~m}$ digunakan untuk analisis vegetasi tingkat pohon yang digambarkan sebagai berikut:

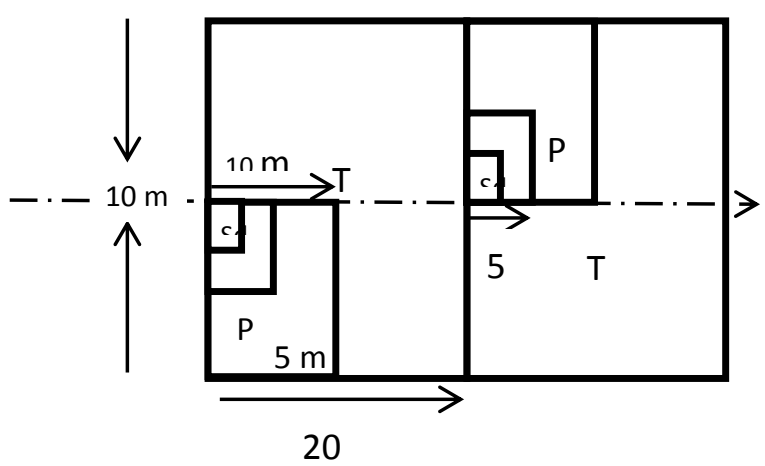

Gambar 3. Petak ukur vegetasi

Keterangan:

$\mathrm{T}=$ Pohon $(20 \mathrm{~m} \times 20 \mathrm{~m})$,

$P=$ Tiang $(10 \mathrm{~m} \times 10 \mathrm{~m})$,

Sp = Pancang $(5 \mathrm{~m} \times 5 \mathrm{~m})$, dan

Sd $=$ Semai $(2 \mathrm{~m} \times 2 \mathrm{~m})$.

Parameter dalam analisis vegetasi adalah sebagai berikut :

Kerapatan Jenis (Di) adalah jumlah tegakan jenis ke-I dalam suatu area.

Kerapatan Jenis $(\mathrm{Di})=\frac{\sum n i}{\text { Luas petak contoh }(A)}$

Dimana (Di) adalah kerapatan jenis ke-i, (ni) adalah jumlah total tegakan dari suatu jenis dan A adalah luas total area pengambilan contoh (luas total petak contoh (plot) dalam $\mathrm{m}^{2}$.

Kerapatan Relatif Jenis (RDi) (\%) adalah perbandingan antara jumlah tegakan jenis ke-i dan jumlah tegakan seluruh jenis $\left(\sum n\right)$

$$
\mathrm{RDi}=\frac{n i}{\sum n} \times 100 \%
$$

Frekuensi Jenis (Fi) adalah peluang ditemukannya jenis ke-i, dalam petak contoh yang diamati.

$$
\text { (Fi) }=\frac{p i}{\sum p}
$$

Dimana Fi adalah frekuensi jenis i, pi adalah jumlah petak contoh/plot dimana ditemukan jenis i, dan $\Sigma \mathrm{p}$ adalah jumlah total petak contoh/ plot yang diamati.

Frekuensi Relatif Jenis (RFi) (\%) adalah perbandingan antara frekuensi jenis i (Fi) dan jumlah frekuensi untuk seluruh jenis $(\Sigma F)$.

$$
\mathrm{RFi}=\frac{F i}{\sum F} \times 100 \%
$$

Jumlah nilai kerapatan relatif jenis (RDi), frekuensi relatif jenis (RFi) dan penutupan relatif jenis (RCi) menunjukkan Indeks Nilai Penting (INP) untuk masing-masing jenis.

$$
I N P=R D i+R f i+R c i
$$

Nilai Penting suatu jenis berkisar antara 0-300. Indeks ini memberikan suatu gambaran mengenai pengaruh atau peranan suatu jenis.

\section{Indeks Keragaman}

Nilai indeks keanekaragaman $\left(\mathrm{H}^{\prime}\right)$ berhubungan dengan kekayaan spesies pada lokasi tertentu, tetapi juga dipengaruhi oleh distribusi kelimpahan spesies. Jika diasumsikan distribusi menyebar normal, maka pada kisaran 100 spesies akan didapatkan nilai $\mathrm{H}^{\prime} \approx 3$, dan untuk mendapatkan $\mathrm{H}^{\prime}>5$ diperlukan 105 spesies.

$$
\text { Shannon Index: } \mathrm{H}^{\prime}=-\sum_{i=1}^{s} p i \ln p i
$$

Keterangan :

$\mathrm{H}^{\prime}$ = Indeks diversitas Shannon-Wiener

$s \quad=$ jumlah spesies

$p i=\mathrm{ni} / \mathrm{N}$

$n i=$ jumlah individu jenis $\mathrm{i}$

$N=$ total individu di seluruh plot 
Indeks Keragaman Shannon-Wiener $\left(\mathrm{H}^{\prime}\right)$, Indeks tersebut dikemukakan dengan rumus seperti dibawah:

Dimana:

$$
H^{\prime}=-\sum \begin{gathered}
(p i \operatorname{In} p i) \\
i=1
\end{gathered} \quad ; p i=n i / N
$$

$H^{\prime} \quad$ = Indeks keragaman;

pi = Proporsi individu taksa ke $i$;

ni = Jumlah individu taksa- $i$; dan

$\mathrm{N}=$ Total jumlah taksa

\section{Hasil dan Pembahasan}

\section{Analisis Vegetasi di Stasiun 1 (Sebelah Utara} Mata Air Tiga Rasa)

Terdapat 4 jenis tumbuhan dalam tingkat semai yakni pakis sayur Diplazium esculentum, Talas Araceae, kopi Coffea arabica, dan suji Dracaena angustifolia. Tumbuhan semai yang memiliki nilai $\mathrm{H}^{\prime}$ tinggi adalah jenis Araceae 0.33. Pada tingkat tiang terdapat jenis waru, jati, dan palem raja. Sedangkan pada tingkat Pancang terdapat Angsana yang memiliki H' 0.21 dan Jati dengan $H^{\prime}$ 0.17. Kemudian dalam tingkat pohon nilai $\mathrm{H}^{\prime}$ tertinggi pada jenis angsana $\mathrm{H}^{\prime} 0.17$. Secara keseluruhan pada Stasiun 1 no 1 memiliki nilai $\mathrm{H}^{\prime} 2.29$ yang artinya dengan nilai $1 \leq \mathrm{H}^{\prime} \leq 3$ maka termasuk keanekaragaman tumbuhan sedang dan kestabilan komunitas sedang.

Hasil analisis vegetasi pada 3 petak didapatkan hasil $\mathrm{H}^{\prime}$ pada petak 1 Nilai H' 2.29 dan pada petak ke $2 \mathrm{H}^{\prime} 2.20$ serta pada petak ke 3 Nilai H' 2.06. Dengan nilai rata-rata 2,18 maka nilai $\mathrm{H}^{\prime}$ dalam rentang $1 \leq \mathrm{H}^{\prime} \leq 3$ sehingga termasuk keanekaragaman tumbuhan sedang dan kestabilan komunitas sedang.

\section{Analisis Vegetasi di Stasiun 2 (Sebelah Timur Mata Air Tiga Rasa)}

Hasil analisis vegetasi pada 3 petak pada stasiun 2 didapatkan hasil $\mathrm{H}^{\prime}$ pada petak 1 Nilai $\mathrm{H}^{\prime} 2.17$ dan pada petak ke $2 \mathrm{H}^{\prime} 2.29$ serta pada petak ke 3 Nilai $\mathrm{H}^{\prime}$ 1.71. H' tertinggi terdapat pada petak 1 dan terendah pada petak 3 . Hal ini disebabkan pada petak 3 terdapat alih fungsi lahan menjadi kamar mandi umum dan wc. Dengan nilai rata-rata 1.9 maka nilai $\mathrm{H}^{\prime}$ dalam rentang $1 \leq \mathrm{H}^{\prime} \leq 3$ sehingga termasuk keanekaragaman tumbuhan sedang dan kestabilan komunitas sedang.

\section{Analisis Vegetasi di Stasiun 3 (Sebelah Selatan Mata Air Tiga Rasa )}

Hasil analisis vegetasi pada 3 petak pada stasiun 3 didapatkan hasil $\mathrm{H}^{\prime}$ pada petak 1 Nilai $\mathrm{H}^{\prime} 1.97$ dan pada petak ke $2 \mathrm{H}^{\prime} 1.49$ serta pada petak ke 3 Nilai $H^{\prime}$ 1.28. $H^{\prime}$ tertinggi terdapat pada petak 1 dan terendah pada petak 3. Dengan nilai rata-rata 1.58 maka nilai $\mathrm{H}^{\prime}$ dalam rentang $1 \leq \mathrm{H}^{\prime} \leq 3$ sehingga termasuk keanekaragaman tumbuhan sedang dan kestabilan komunitas sedang.

\section{Analisis Vegetasi di Stasiun 4 (Sebelah Utara Barat Mata Air Tiga Rasa)}

Hasil analisis vegetasi pada 3 petak pada stasiun 3 didapatkan hasil $\mathrm{H}^{\prime}$ pada petak 1 Nilai $\mathrm{H}^{\prime} 2.25$ dan pada petak ke $2 \mathrm{H}^{\prime} 2.11$ serta pada petak ke 3 Nilai $H^{\prime}$ 1.95. $H^{\prime}$ tertinggi terdapat pada petak 1 dan terendah pada petak 3. Dengan nilai rata-rata 2.1 maka nilai $\mathrm{H}^{\prime}$ dalam rentang $1 \leq \mathrm{H}^{\prime} \leq 3$ sehingga termasuk keanekaragaman tumbuhan sedang dan kestabilan komunitas sedang.

\section{Simpulan}

Nilai rata-rata H' (H Indeks) pada Stasiun 1 (2.19), Stasiun 2 (1.9), Stasiun 3 (1.58) dan, Stasiun 4 (2.1). Hasil rata-rata $\mathrm{H}^{\prime}$ pada keseluruhan stasiun adalah 1.96. Maka vegetasi di sekitar mata air tiga rasa termasuk keanekaragaman tumbuhan sedang dan kestabilan komunitas sedang. Faktor abiotik juga mempengaruhi lingkungan disekitar mata air Tiga Rasa Rejenu.

\section{Daftar Pustaka}

McBirney A. R, Serva L, Guerra M, Connor C. B. 2003. Volcanic and seismic hazards at a proposed nuclear power site in Central Java. Journal of Volcanology and Geothermal Reseach, 126(1-2): 11-30.

Azizah P. N. 2017. Analisis vegetasi di Kawasan Sekitar Mata Air Ngembel, Kecamatan 
Pajangan, Kabupaten Bantul. Jurnal Riset Daerah, 16(1): 2685-2702.

Falah A. 2012. Spiritualitas Muria: Akomodasi tradisi dan wisata. Walisongo, 20(2): 429452.

Sari D. I. 2010. Objek Wisata Religi Makam Sunan Muria. Skripsi. Surakarta: Universitas Sebelas Maret.

Studies M. $2010 . \quad$ Kudus:
Widjanarko M. 2016. Modal sosial Desa Rahtawu: Studi kasus pelestarian Hutan Muria di Kabupaten Kudus. Jurnal Masyarakat \& Budaya. 18(1): 109-120.

Widjanarko M, Wismar'ein D. 2011. Identifikasi sosial potensi ekowisata berbasis peran masyarakat lokal. Jurnal Psikologi Undip. 9(1):33-39.

http://muriastudies.umk.ac.id/. 